\title{
A SPRING-LOADED BOTTOM-SAMPLER
}

\author{
By W. Smith and A. D. McIntyre \\ Marine Laboratory, Aberdeen
}

(Text-figs. I-3)

\section{INTRODUCTION}

For routine sampling of the infauna of the sea bottom an apparatus is required which is simple, easily handled, and which can give samples of consistent volume from different types of bottom and in varying weather conditions.

The Petersen sampler and its modification, the van Veen, are simple and easily handled and give reasonably consistent samples from some types of soil. But on hard ground they are less satisfactory, and in rough weather they tend either to land unevenly on the bottom, thereby taking smaller samples of variable volume, or to release in mid-water with the rolling of the ship, so that no sample is taken.

A new sampler, which is in use at the Plymouth Laboratory, has been described by Holme (1949). We are glad to be able to acknowledge here the kindness of the Director and $\mathrm{Mr}$ Holme in arranging for us the early supply of one of these samplers. However, in spite of its improvements, it has certain disadvantages which are well summed up in the author's own words 'the area sampled $\left(\frac{1}{20} \mathrm{~m}^{2}\right.$.) is, however, rather small, and the apparatus rather heavy, and so difficult to work except in calm weather'. In using Holme's sampler from Aberdeen this last point, the difficulty of using it in anything but calm weather, was found to be its greatest disadvantage.

When bottom-fauna work has to be fitted into a wider programme, it is often impossible to wait for suitable conditions, and the need was still felt for a sampler which could be used with confidence in any weather. The apparatus described here was designed and constructed, by the first author, in an effort to produce a sampler which would give consistent results even in bad weather and on 'difficult' grounds. It was constructed at the Northern Engineering Works, Peterhead, and we wish to express our thanks to the proprietors for their interest and assistance.

\section{THE SAMPLER}

The apparatus is shown in Fig. I. It consists essentially of a spring-loaded bucket carried in a frame. In use, when the apparatus comes to rest squarely on the bottom, the springs are released and drive the bucket into the soil; hauling on the warp then closes the sampler.

The bucket, which is semicircular in cross-section, is hinged on an axle along the centre line, and is opened and closed by means of two arms (Fig. $3 \mathrm{~A}$ ). 
It is carried by an inverted U-shaped bridle which is attached at both ends of the axle. The horizontal bar of the bridle is bored so that the bridle and bucket can move vertically on a tubular guide (Fig. I) fixed at the centre of the frame. This vertical movement is limited to 3 in. by stops. Two springs

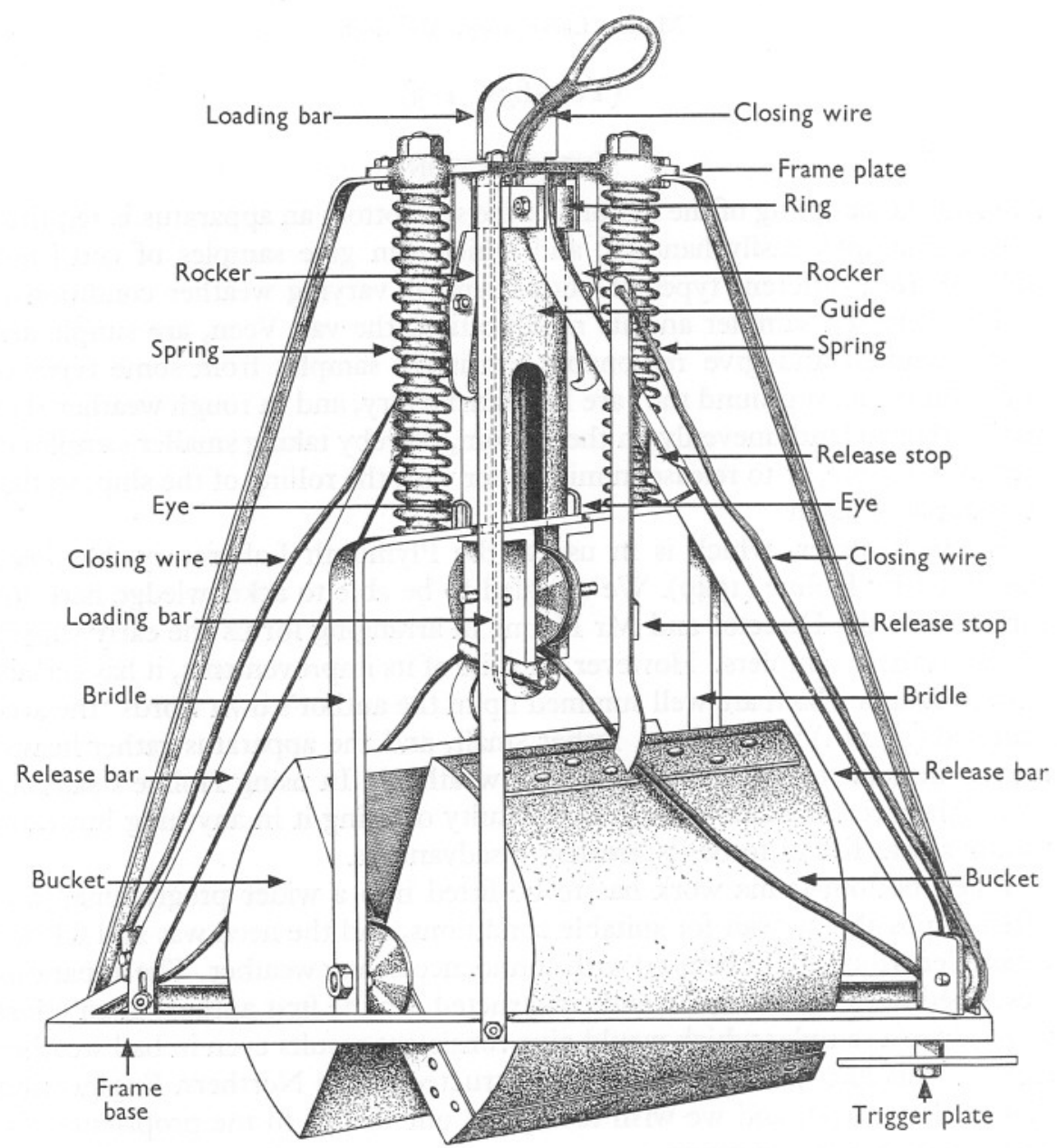

Fig. I. Diagram of sampler, in the unloaded position (overall dimensions, $26 \times 26 \times 20$ in.).

(each loading $50 \mathrm{lb}$./in.) are placed so that their lower ends bear against the bridle and their upper ends against the underside of the frame plate. Each spring is located by an internal rod on the bridle (Fig. $3 \mathrm{~A}$ ) which slides into a tube attached to the frame plate. To the middle of the bridle is secured a loading bar which passes up the centre of the guide and projects through the frame plate. In loading, this bar is pulled up by means of a loading lever, 
and the bucket is raised against the pressure of the springs until two eyes on the bridle come within reach of two rockers attached to the frame plate. The rockers engage in the eyes and hold the bucket in the loaded position against the pressure of the springs. The faces of the rockers bearing in the eyes are set at such an angle that a horizontal component of the pressure tends to free the rockers from the eyes, releasing the bucket. This movement of the rockers is prevented by a ring against which the upper ends of the rockers bear when

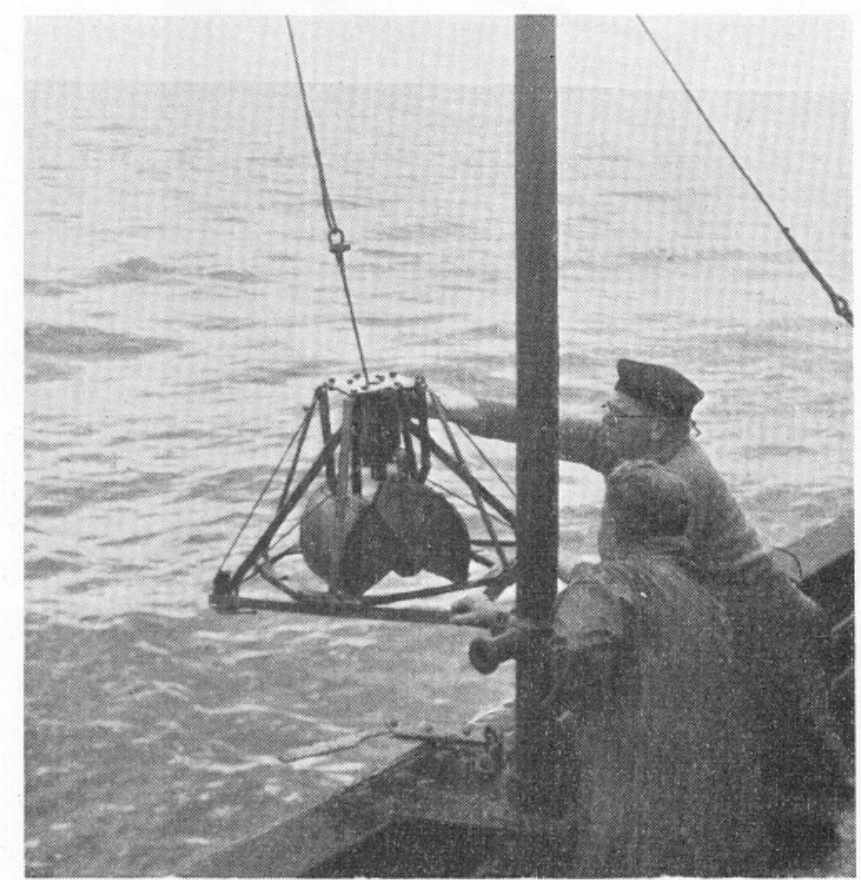

Fig. 2. The sampler in use at sea. The instrument is set and is about to be lowered. The loading bar has been removed.

the apparatus is in the loaded position. The ring is fixed by knuckle joints to two release bars which terminate in trigger plates below the frame at diagonally opposite corners. When the sampler strikes the bottom squarely, the pressure on both trigger plates causes the ring to move up. This allows the rockers to swing free of the eyes and the open bucket is forced into the soil by the springs. When the instrument is set the loading bar may be removed (as in Fig. 2), but when the sampler is in continuous use it has been found convenient to leave the bar in position.

A wire attached to the end of each arm of the bucket passes over pulleys on the frame and bridle, up through the centre of the guide, and is shackled above the frame plate to the warp from the ship. When the sampler is being lowered the closing wire bears the weight, and the bucket is prevented from closing by 


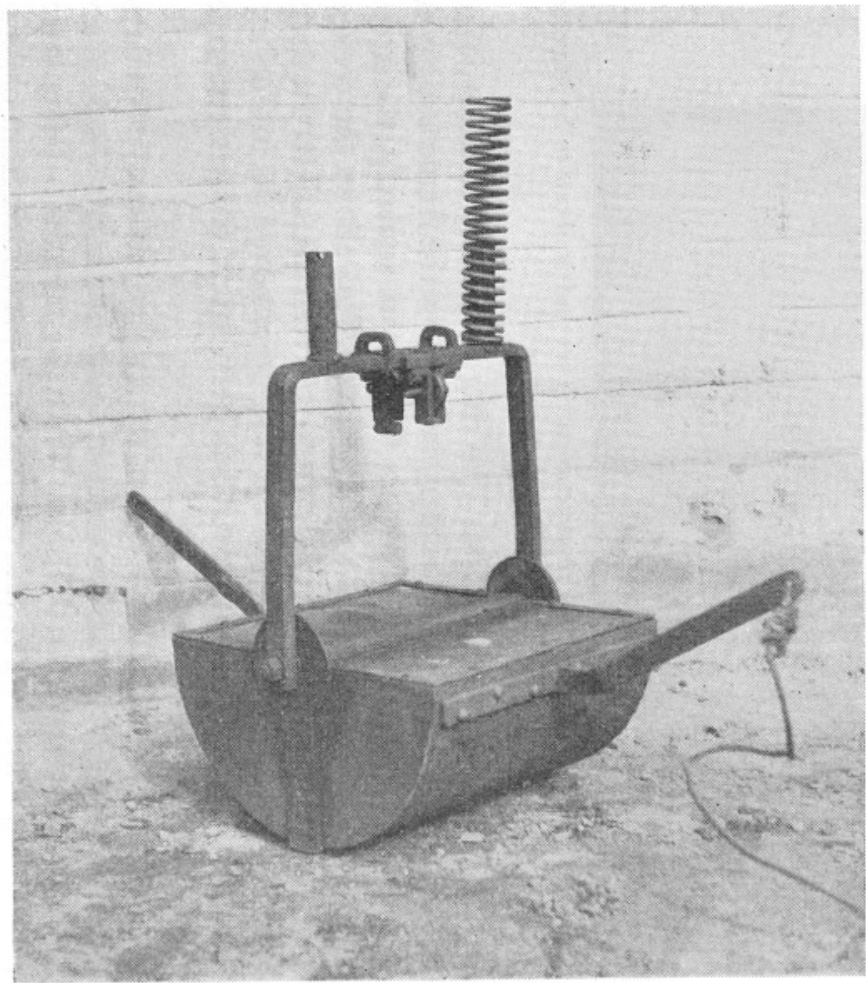

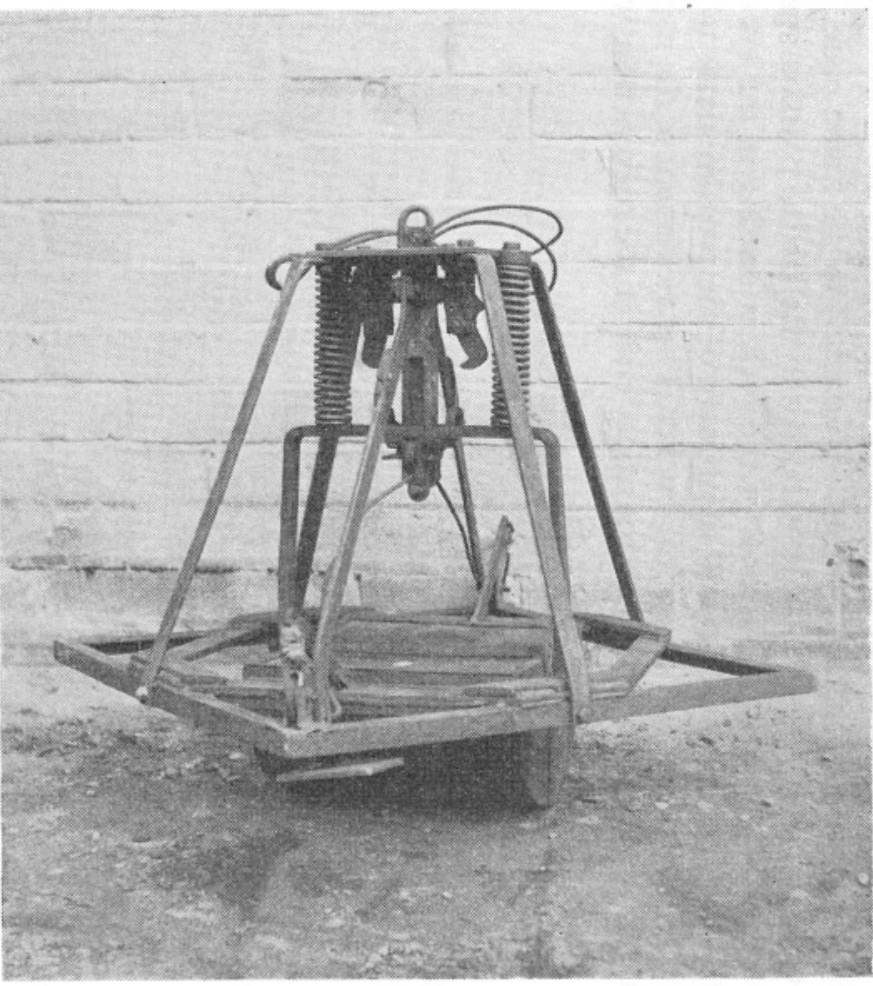


stops on the arms bearing against similar stops on the release bars (Fig. I). The release of the bucket when the sampler hits the bottom disengages the arms from the stops so that hauling on the warp first closes the bucket, then lifts the sampler off the bottom.

The bucket has a radius of $17 \frac{1}{2} \mathrm{~cm}$. and a length of $32 \mathrm{~cm}$., and is constructed of $\frac{1}{8}$ in. $\left(3.2 \mathrm{~mm}\right.$.) sheet metal. The area of bottom sampled is $\frac{1}{10} \mathrm{~m} .{ }^{2}$. The top of the bucket is covered with fine-mesh gauze. The arms which are riveted to the bucket are $28 \mathrm{~cm}$. long and are of $\mathrm{I} \times \frac{1}{4}$ in. flat iron. The bridle is made from two pieces of $\mathrm{I} \frac{1}{4} \times \frac{1}{2}$ in. flat iron bent at right angles, and welded to a $\frac{1}{2}$ in. plate 3 in. square which is bored to slide on the central guide. The guide is $\mathrm{IO}$ in. long and of $I \frac{3}{4}$ in. diameter tube. It has a $\frac{3}{4}$ in. slot on each side extending upwards from the lower end for 5 in. The base of the frame consists of four bars of $\mathrm{I} \times \frac{1}{8}$ in. angle iron 26 in. long, and from each side of the frame an upright bar of $\mathrm{I} \times \frac{1}{4}$ in. flat iron runs to the frame plate, which is 8 in. square and $\frac{1}{4}$ in. thick. The angle iron used for the base proved to be too light, and was strengthened by cross-bars (see Figs. 2 and $3 \mathrm{~B}$ ). The loading bar is $I \times \frac{1}{4}$ in. flat iron and has a loop welded to the top. The apparatus is $20 \mathrm{in}$. high and weighs $100 \mathrm{lb}$. (45 kg.).

\section{RESULTS}

Previous work (Thamdrup, I938) indicates that the van Veen is more efficient than the Petersen grab, and experience at Aberdeen with the van Veen, Petersen, and Plymouth samplers has shown that the van Veen was the most satisfactory over a wide range of conditions. The van Veen has thus been in general use at Aberdeen, and since it is obvious that any new sampler must be compared with the most efficient of the older models, tests have been carried out using the $\frac{1}{10} \mathrm{~m}^{2}$. van Veen and the Smith sampler.

The samplers were used from the ship at anchor on various grounds and at different depths, the order of use being determined from a table of random numbers. The volumes, in litres, of material taken in each sample are set out below:

(I) Dornoch Firth, $9 \mathrm{~m}$. depth, muddy sand

$\begin{array}{lllll}\text { Smith sampler } & 3.75 & 3.5 & 2.5 & 3.25 \\ \text { v. Veen sampler } & 4.0 & 3.5 & 3.0 & 2.5\end{array}$

(2) Dornoch Firth, I3 m. depth, muddy sand $\begin{array}{lllll}\text { Smith sampler } & 4.5 & 2.5 & 4.5 & 4.5\end{array}$ $\begin{array}{lllll}\text { v. Veen sampler } & 2 \cdot 25 & 2 \cdot 5 & 2 \cdot 25 & 2 \cdot 0\end{array}$

(3) Dornoch Firth, $24 \mathrm{~m}$. depth, muddy gravel $\begin{array}{lllll}\text { Smith sampler } & 4.75 & 4.75 & 5.0 & 4.0\end{array}$ $\begin{array}{lllll}\text { v. Veen sampler } & 3.25 & 4.0 & 3.0 & 2.75\end{array}$

(4) Dornoch Firth, $24 \mathrm{~m}$. depth, mud $\begin{array}{lllll}\text { Smith sampler } & 5.0 & 4.0 & 4.75 & 5.5\end{array}$ $\begin{array}{llll}\text { v. Veen sampler } \quad 3.0 & 3.0 & 3.5 & 3.25\end{array}$

(5) Aberdeen Bay, $37 \mathrm{~m}$. depth, hard sand $\begin{array}{lllll}\text { Smith sampler } & 3.5 & \text { I. } 5 & 4.0 & 4.0\end{array}$

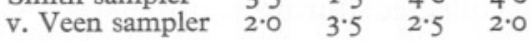

Mean 3.25 per $\frac{1}{10} \mathrm{~m} .^{2}$

Mean 3.25

Mean 4.0 per $\frac{1}{10} \mathrm{~m}^{2}$

Mean $2 \cdot 25$

Mean 4.6 per $\frac{1}{10} \mathrm{~m}^{2}$

Mean $3 \cdot 25$

Mean 4.8 per $\frac{1}{10} \mathrm{~m} .^{2}$

Mean $3 \cdot 2$

$\begin{array}{lll}3.5 & 3.5 & 3.0 \\ 1.5 & 0.5 & 3.5\end{array}$

Mean 3.3 per $\frac{1}{10} \mathrm{~m} .^{2}$ Mean $2 \cdot 2$ 
For test number (5) above, a detailed analysis was made and the frequencies of the various organisms taken are shown in Table I. In nearly every comparison the Smith sampler gave a higher population estimate, and statistical analysis showed that the difference between the two samplers in this respect was significant at the $\mathrm{I} \%$ level.

\section{TABLE I}

Aberdeen Bay. Depth $37 \mathrm{~m}$. Bottom, hard sand. The mean numbers of animals taken in seven dips with the van Veen and Smith samplers respectively.

\begin{tabular}{|c|c|c|}
\hline & $\begin{array}{c}\text { van Veen } \\
\text { sampler }\end{array}$ & $\begin{array}{l}\text { Smith } \\
\text { sampler }\end{array}$ \\
\hline Gastropods & 0.1 & $2 \cdot 0$ \\
\hline Nucula & $20 \cdot 4$ & $23 \cdot 0$ \\
\hline Thyasira & $I \cdot I$ & $\mathrm{r} \cdot 3$ \\
\hline Montacuta & $2 \cdot 7$ & $\mathrm{I} \cdot 6$ \\
\hline Cyprina & $r \cdot 3$ & $2 \cdot 3$ \\
\hline Dosinia & $\mathrm{II} \cdot \mathrm{I}$ & $13 \cdot 6$ \\
\hline Venus fasciata & $2 \cdot 3$ & 3.9 \\
\hline Tellina fabula & $5 \cdot 6$ & $6 \cdot I$ \\
\hline Abra & 3.9 & $6 \cdot I$ \\
\hline Gari fervensis & $\mathrm{I} \cdot 3$ & $I \cdot I$ \\
\hline Cultellus & 0 & 0.4 \\
\hline Thracia & $\mathrm{I} \cdot 6$ & $2 \cdot 3$ \\
\hline Other lamellibranchs & 0.3 & 0.7 \\
\hline Ophiuroids & 3.0 & $4 \cdot 4$ \\
\hline Echinoids & 3.9 & $4 \cdot 0$ \\
\hline Crustacea & 3.4 & $6 \cdot 0$ \\
\hline Aphroditidae & 2.0 & $2 \cdot 4$ \\
\hline Goniada & $2 \cdot 9$ & $3 \cdot 3$ \\
\hline Nepthys & $\mathrm{I} \cdot 7$ & $2 \cdot 6$ \\
\hline Lumbriconereis & $\mathrm{I} \cdot 3$ & $\mathrm{I} \cdot 6$ \\
\hline Other errant polychaetes & 0.3 & $I \cdot I$ \\
\hline Ariciidae & $2 \cdot 9$ & $5 \cdot I$ \\
\hline Spionidae & $0 \cdot 7$ & $2 \cdot 0$ \\
\hline Magelona & 0.3 & $1 \cdot 0$ \\
\hline Cirratulidae & $\mathrm{I} \cdot 7$ & $2 \cdot 0$ \\
\hline Chlorhaemidae & $I \cdot 3$ & $\mathrm{I} \cdot 6$ \\
\hline Other sedentary polychaetes & 0.7 & 0.9 \\
\hline
\end{tabular}

On two occasions the new sampler was compared with a $\frac{1}{5} \mathrm{~m} \cdot{ }^{2}$ Petersen grab, with the following results (volumes in litres):

(I) Smith Bank, $37 \mathrm{~m}$. depth, fine sand

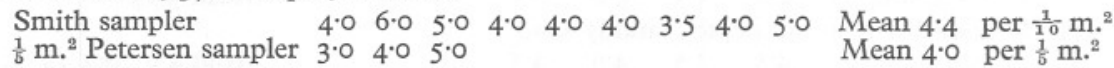

(2) Off Smith Bank to northwest, $73 \mathrm{~m}$. depth, mud

$\begin{array}{llllllllll}\text { Smith sampler } \quad 2.5 & 2.0 & 4.0 & 5.0 & 2.5 & 2.0\end{array}$

$\frac{1}{5} \mathrm{~m}^{2}$ Petersen sampler $2.5 \quad 3.0$

Mean 3.0 per $\frac{1}{10} \mathrm{~m} \cdot{ }^{2}$ Mean 2.75 per $\frac{1}{5} \mathrm{~m}^{2}{ }^{2}$

It is of interest that the smaller sampler tended to take a larger volume.

Apart from such specific tests, an indication of the relative performance of the two samplers is given by figures collected during routine surveys over 
a period of several months. The following comparisons are from recent data (volumes in litres):
(I) Smith Bank, $37-40 \mathrm{~m}$. depth, fine sand
Smith sampler 52 dips Mean volume 3.9 Range r.0-7.0.
v. Veen sampler 165 dips Mean volume 3.4 Range 0.25-6.0.
(2) Smith Bank, 37-40 m. depth, shell gravel
$\begin{array}{rrrr}\text { Smith sampler } & 9 \text { dips } & \text { Mean volume } 5 \cdot 0 & \text { Range } 4 \cdot 0-7 \cdot 0 . \\ \text { v. Veen sampler } & \text { I5 dips } & \text { Mean volume } 4 \cdot 5 & \text { Range } 0 \cdot 5-6 \cdot 0 .\end{array}$

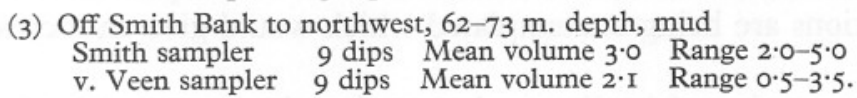

\section{Discussion}

The above tests show that the new sampler is more efficient than the van Veen in the areas visited. Perhaps the most significant feature, however, is not shown by these data. The opportunity to compare the two instruments usually arose during a general bottom-sampling programme. On several occasions the comparison had to be abandoned because bad weather prevented the van Veen from operating. On each occasion, however, it was found possible to complete the programme with the Smith sampler only, which continued to give samples of reasonably consistent volume even under the most trying weather conditions.

The success of the new sampler in bad weather is due to its inability to release until resting squarely on the bottom. If it strikes the bottom unevenly only one of the release arms is operated and, since the arms are connected to the ring by knuckle joints, movement of one arm merely causes the ring to pivot. Release cannot take place until the other arm is also raised, i.e. until the apparatus is settled on the bottom.

A distinctive feature of the new sampler is connected with its method of closing. A great part of the superiority of the van Veen over the Petersen grab is probably due to the leverage effect exerted by the arms in closing the jaws. This leverage effect is greatest when the van Veen is fully open, and decreases as the jaws close and the arms come together. In the new sampler, however, the pull on the arms is downward, and the leverage effect increases as the sampler digs into the ground and reaches a maximum as the jaws come together.

Another feature of the new sampler is the gauze covering on top of the bucket. Because of this the down-wave produced on descent is relatively small, and this may help to account for the high proportion of active surfacedwelling forms, such as euphausiids and amphipods which have been found in the new sampler. In surveys of Smith Bank, for example, the new sampler took on the average twice as many amphipods as the van Veen. Samplers with a solid upper surface must set up a considerable down-wave, and this will tend to wash small surface animals out of the sampler's reach. It is also important 
that, since the bucket closes completely, no material is lost in hauling. Further, the mesh of the gauze covering is considerably finer than that of the gauze used in sieving.

In its present form, the theoretical maximum depth to which the new sampler can bite is $7 \mathrm{~cm}$., and it is of interest to note that the depth to which it has in fact been digging, calculated from its average volume of 41 ., is $6.7 \mathrm{~cm}$. It is felt that there is a considerable reserve of power in the sampler, and alterations are being contemplated which would give an increased depth of bite.

Once the routine of loading and operating the new sampler has become familiar, it can be used almost as quickly as the van Veen. Working from F.R.S. Explorer at a depth of $40 \mathrm{~m}$. the average time taken to complete three dips with the van Veen was I4 min., and with the new sampler I5 min.,a negligible difference.

\section{SUMMARY}

A new bottom-sampler is described. It covers a surface area of $\frac{1}{10} \mathrm{~m} \cdot{ }^{2}$ and digs to a depth of almost $7 \mathrm{~cm}$. The sampler consists of a bucket which is driven into the soil by springs and is closed by the hauling in of the warp. The apparatus can sample only when resting squarely on the bottom, and was designed to work on hard sand and in bad weather. It has been shown to be successful in both these respects.

Specific tests and experience under various conditions show it to be more generally satisfactory than any of the other samplers used.

\section{REFERENCES}

Holme, N. A., 1949. A new bottom-sampler. F. Mar. biol. Ass. U.K., Vol. 28, pp. 323-32.

Thamdrup, H. M., 1938. Der van Veen-Bodengreifer. Vergleichsversuche über die Leistungsfähigkeit des van Veen- und des Petersen-Bodengreifers. F. Cons. int. Explor. Mer, Vol. I3, pp. 206-I2. 